\title{
8
}

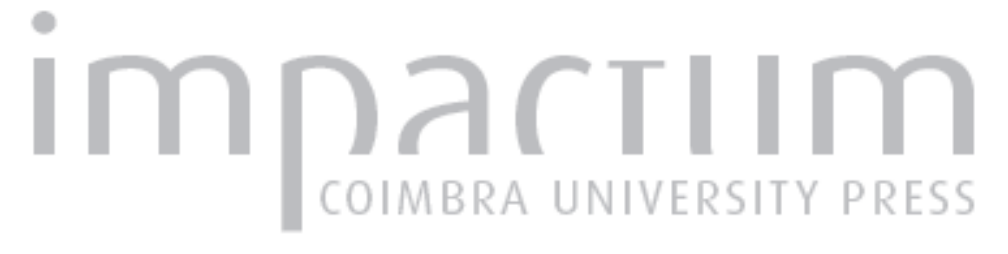

\section{Páginas de Suetónio: a morte ignóbil de Vitélio}

Autor(es): Brandão, José Luís

Publicado por: Imprensa da Universidade de Coimbra

URL persistente:

URI:http://hdl.handle.net/10316.2/41468

DOI: $\quad$ DOI:https://doi.org/10.14195/0872-2110_60_6

Accessed : $\quad$ 26-Apr-2023 10:26:20

A navegação consulta e descarregamento dos títulos inseridos nas Bibliotecas Digitais UC Digitalis, UC Pombalina e UC Impactum, pressupõem a aceitação plena e sem reservas dos Termos e Condições de Uso destas Bibliotecas Digitais, disponíveis em https://digitalis.uc.pt/pt-pt/termos.

Conforme exposto nos referidos Termos e Condições de Uso, o descarregamento de títulos de acesso restrito requer uma licença válida de autorização devendo o utilizador aceder ao(s) documento(s) a partir de um endereço de IP da instituição detentora da supramencionada licença.

Ao utilizador é apenas permitido o descarregamento para uso pessoal, pelo que o emprego do(s) título(s) descarregado(s) para outro fim, designadamente comercial, carece de autorização do respetivo autor ou editor da obra.

Na medida em que todas as obras da UC Digitalis se encontram protegidas pelo Código do Direito de Autor e Direitos Conexos e demais legislação aplicável, toda a cópia, parcial ou total, deste documento, nos casos em que é legalmente admitida, deverá conter ou fazer-se acompanhar por este aviso.

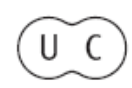


COIMBRA • 2015

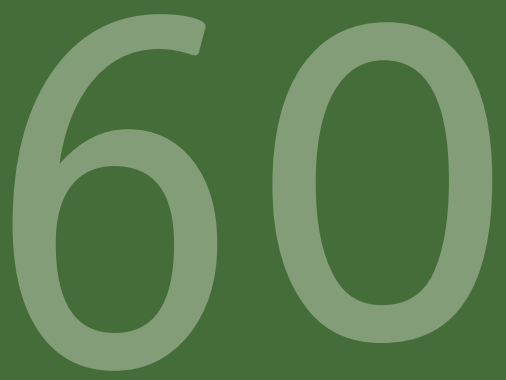

\title{
BOLETIM DE
}

\section{ESTUDOS CLÁSSICOS}

\author{
ASSOCIAÇÃO \\ PORTUGUESA \\ DE ESTUDOS \\ CLÁSSICOS \\ INSTITUTO \\ DE ESTUDOS \\ CLÁSSICOS
}




\title{
PÁGINAS DE SUETÓNIO: A MORTE IGNÓBIL DE VITÉLIO
}

\section{ACCOUNTS OF SUETONIUS: THE SHAMEFUL DEATH OF VITELLIUS}

\author{
JOSÉ LUÍS BRANDÃO \\ CECH - UNIVERSIDADE DE COIMBRA \\ iosephus@fl.uc.pt
}

Resumo: A fechar o ciclo de conflitos que se sucede à morte de Nero, a narrativa da execução pública de Vitélio transmitida por Suetónio constituiu o relato de morte onde mais ostensivamente se manifesta a hostilidade do biógrafo para com um imperador. Suetónio escolhe os elementos mais aviltantes que encontra na tradição, de modo a transformar os últimos momentos daquele imperador no merecido castigo de uma vida indigna.

Palavras-chave: Vitéli; Césares; Suetónio; Império Romano; Biografia.

Abstract: The public execution of Vitellius, recounted by Suetonius in the context of the turbulent cycle that succeed the Nero's death, seems to be the more ostensible manifestation of the biographer's hostility towards an emperor. In fact, Suetonius selects from the tradition the more dishonourable elements, in order to transform the last moments of Vitellius in the deserved punishment for a contemptible life.

Keywords: Vitellius; Caesars; Suetonius; Roman Empire; Biography.

Depois de termos apresentado no volume anterior o relato suetoniano de uma morte modelar - a de Augusto ${ }^{1}$ - trazemos ao leitor a morte mais

\footnotetext{
${ }^{1}$ Vide Brandão 2011: 61-73.
} 
execrável das Vidas dos Césares; um assassínio que de facto é o castigo de um tipo de vida, em que certos vícios são levados ao limite do tolerável.

Toda a Vida de Vitélio parece construída de modo a justificar este fim $^{2}$. Trata-se de tornar a vida odiosa ao máximo para que a morte se transforme no merecido desenlace. E nesta tarefa se empenha o biógrafo desde o início. Suetónio mostra que não aprecia de modo algum Vitélio e trata-o da pior forma possível, talvez pelo facto de o seu pai ter militado no exército de Otão, imperador que foi derrotado pelas tropas de Vitélio e que se suicidou para evitar o prolongamento da guerra civil, ganhando uma fama que redimiu uma vida considerada dissoluta.

O biógrafo procura demonstrar que toda a vida de Vitélio é negativa, que ele é odiado pelos próprios deuses e um desfavorecido da fortuna. Ao conhecerem o horóscopo do recém-nascido, os progenitores horrorizaram-se tanto que o pai se opõe a que lhe confiem uma província, e a mãe, ao saber que ele tinha sido enviado às legiões e proclamado imperador, lamenta-o como perdido (Suet. Vit. 3.2).

O objecto da biografia é o ethos, e, no que toca à fundamentação do carácter, o biógrafo descreve-o por associação aos vícios caracterizadores dos Júlio-Cláudios: que teria passado a meninice e a primeira adolescência entre os supostos prostitutos de Tibério em Cápreas, o que não passava de rumor fabricado sobre rumores (Suet. Vit. 3.2); que teve o favor de Gaio pela comum paixão pelas corridas do circo, o favor de Cláudio, pela paixão pelo jogo dos dados, e o favor de Nero, pelas mesmas paixões e porque, ao presidir aos jogos Neronianos, se juntara aos que instavam o imperador a participar no concurso dos citaredos, para ir ao encontro dos desejos tácitos de Nero (Suet. Vit. 4).

O seu principal defeito é a gula. Galba envia-o para a Germânia Inferior, numa nomeação que é mais por desprezo que por mercê, no pressuposto de que os homens menos perigosos são os que só pensam em comer; e com a abundância da província podia satisfazer a sua

\footnotetext{
${ }^{2}$ Como sugere Cizek 1975: 129.
} 
goela insaciável (Suet. Vit. 7.2). Certamente não seria esta a razão, mas a verdade é que, graças a uma nomeação desprestigiante, Vitélio vai estar no sítio certo no momento certo. É, pois, investido da púrpura imperial pelos soldados da Germânia, num acto solene assaz aviltado pelo biógrafo ${ }^{3}$, na mira de criar uma unidade da narrativa. Os relatos de Tácito e_Plutarco mostram que a aclamação não foi assim tão desorganizada $^{4}$, nem a atitude do aclamado tão passiva como Suetónio sugere ${ }^{5}$. Mas este é o princípio do fim de Vitélio, como previram os seus pais.

\section{O CONTEXTO}

O contexto mais vasto desta morte é o da crise de 68-69 d.C., os conflitos que se seguiram ao suicídio de Nero em Junho de 68 d.C., um período de convulsão que convém aqui caracterizar em traços gerais. Num curto espaço de tempo desfilaram em Roma quatro imperadores, Galba, Otão, Vitélio e Vespasiano. Só o último vingou e deu origem à dinastia dos Flávios.

A revolta contra Nero estalou na Gália, na Primavera de 68 d.C., com Víndex, um governador da Gália Lugdunense, de ascendência gaulesa. Quando Galba, que então governava a Hispânia, se juntou à revolta por instigação de Víndex, a situação agravou-se para Nero. É que o velho general, além de ser oriundo de uma antiga e pura cepa romana, era próximo de Lívia, prestara grandes serviços e acumulara honras nos principados de Calígula e Cláudio, dera provas de rigor na administração das províncias e era modelo de austeridade à moda

\footnotetext{
${ }^{3}$ Suet. Vit. 8.1. Vide Martin 1991: 229-230.

${ }^{4}$ Cf. Tácito, Hist. 1.55-57, e Plutarco, Gal. 22. Suetónio, ao construir cada Vida separadamente, desmembra a narrativa entre as biografias de Galba (Gal.16.2) e a de Vitélio, desvalorizando o contributo decisivo da armada de Germânia Superior. Vide Murison 1992: 149-150; Gascou 1984: 423.

${ }^{5}$ Vide Venini 1974: 997-2000 e Venini 1977: 118-119.
} 
antiga. Contra ele tinha a idade avançada e a falta de filhos para garantir a sucessão. Apesar de Víndex ser derrotado por Virgínio Rufo, o comandante da Germânia Superior, o movimento revolucionário já estava em marcha e afectou o equilíbrio de forças na Urbe. Abandonado pelos pretorianos e declarado inimigo público pelo senado, Nero, em fuga, é forçado ao suicídio. Galba, reconhecido pelo senado, faz uma caminhada triunfal em direcção a Roma.

Mas a elogiada austeridade de Galba já não estava na moda. Certas medidas de contenção geram descontentamento. Foi determinante a recusa em atribuir aos soldados o prémio que o prefeito do Pretório, Ninfídio Sabino, lhes tinha prometido, quando os instou a abandonarem Nero e prestarem o seu juramento a Galba. As medidas do novo imperador acabam por ser caracterizadas por Suetónio como avareza de carácter, que, aliada a uma actuação incoerente e venal, levada a cabo pelos poderosos libertos (Vínio, Lacão, Ícelo), gerou o descontentamento de todas as ordens e das tropas.

Também o exército da Germânia Superior se agitava, por ver defraudadas as suas aspirações pela vitória sobre Víndex ${ }^{6}$, e rejeitavam um imperador eleito na Hispânia. A revolta alastrou ao exército da Germânia Inferior, comandado por Aulo Vitélio, general que, embora dado aos prazeres da comida e da bebida, era da mais ilustres famílias de Roma; ele próprio próximo de Calígula, de Cláudio e de Nero (Suet. Vit. 4-5). E assim Vitélio foi aclamado por um exército desejoso de maior protagonismo na política de Roma.

Par atalhar o óbice de ser idoso e não ter filhos, Galba tratou de adoptar um jovem nobre, que seria o seu sucessor. A escolha de Galba recaiu sobre L. Calpúrnio Pisão Frúgi Liciniano, jovem ilustre que dava provas de grande elevação moral. Mas os pretorianos preferiam Otão, um antigo amigo de Nero, com fama de licencioso e perdulário. Este governador da Lusitânia (para onde Nero o afastara, talvez por razões

\footnotetext{
${ }^{6} \mathrm{O}$ seu popular comandante, Virgínio Rufo, fora substituído de modo pouco honroso, depois de haver recusado o cargo de imperador que os soldados lhe ofereciam.
} 
passionais relacionadas com Popeia Sabina), cedo se ligara à revolta de Galba e esperava vir a ser adoptado por ele, pelo que não se poupava a despesas para conciliar o favor dos soldados.

Ao desapontamento de Otão, por ter sido preterido, associou-se o ressentimento dos pretorianos, por Galba também então, ao anunciar a adopção diante da parada, lhes não conceder o donativo. Em poucos dias, Otão foi aclamado pelos soldados, e, no dia 15 de Janeiro de 69 d.C., Galba e Pisão foram assassinados no Foro.

O novo imperador conseguiu granjear o favor do senado e do povo ao castigar Tigelino, o prefeito do pretório culpado de muitas atrocidades durante o principado de Nero, e ao proceder com moderação e justiça. Mas agora havia o problema de Vitélio, entretanto aclamado imperador. Como não foi possível um acordo entre as duas partes, a guerra estava de novo no horizonte.

Os exércitos encontraram-se no norte de Itália, e a batalha principal deu-se em Abril de 69, em Betríaco, pequena cidade perto de Cremona, com desfecho desfavorável para Otão, embora o resultado não se apresentasse definitivo. Estavam, de facto, a caminho tropas da Mésia, mas Otão decidiu sacrificar-se para que não houvesse mais guerra civil por sua causa e trespassou o peito com um punhal - um acto que lhe granjeou boa fama, tanto mais que tratou, antes, da salvaguarda dos senadores e amigos que com ele estavam. A histeria colectiva ocorrida no seu funeral torna patente a devoção dos soldados.

De qualquer modo, uma nova frente avançava que colocava de novo tudo em aberto. No Oriente, as tropas aclamaram Vespasiano, que antes se tinha mostrado favorável a Otão.

Procuram-se as causas para tal crise. Para Tácito (Hist. 1.4.2), foi revelado um arcano do império: «o princeps podia ser aclamado em outro lado que não em Roma» - abriu-se assim um precedente no sistema que tornava o império frágil, pois facultava o caminho a usurpadores. Plutarco, no primeiro capítulo da Vida de Galba, atribui as culpas da 
situação aos impulsos irracionais dos soldados, que põem à prova o carácter dos generais, e à sua avidez desenfreada ${ }^{7}$. 0 religioso Suetónio prefere buscar as causas nos desígnios dos deuses, pelo que multiplica os presságios (entre muitos outros, a abrir a Vida de Galba e a encerrar a de Vitélio), e no carácter dos protagonistas, como impõem os ditames da biografia.

Por isso, o biógrafo insiste nos vícios de Vitélio e no seu destino, mas também na sua impiedade. Refere, desde logo, palavras nefandas de Vitélio perante os concidadãos mortos na batalha de Betríaco, agravadas pelo acto de beber na presença dos cadáveres (Suet. Vit. 10.3), actos que o biógrafo qualifica de uanitas e insolentia. Faz uma entrada na cidade arrogante, de armas à vista, e seguem-se outras atitudes que desrespeitam quer o direito divino, quer o humano (Suet. Vit. 11.1-2).

Como governante, o comportamento é modelado sobre o estereótipo de Nero: diz-se mesmo que ofereceu no campo de Marte um sacrifício aos Manes daquele imperador, alegadamente «para que não houvesse dúvidas sobre o modelo do seu governo» (o que parece exagero ${ }^{8}$ ) e pediu a um citaredo que, num banquete solene, cantasse uma composição da autoria de Nero, tornando claro que era autêntico o seu anterior entusiasmo pela actuação do príncipe histrião.

O alegado decalque de Nero é no que deste ficara de pior. Vitélio, segundo o biógrafo, é dominado por dois vícios principais, a luxuria e a saeuitia (Vit. 13.1). o primeiro manifestava-se nos exageros e no exotismo da mesa: fazia um banquete de cada uma das refeições do dia e aguentava-se, graças ao recurso ao vómito. Reiteram-se os gastos com pratos enormes e requintados (como um que denomina como 'escudo de

\footnotetext{
${ }^{7}$ Vide Scuderi 1995: 405-406.

${ }^{8}$ Suet. Vit. 11.2: et ne cui dubium foret, quod exemplar regendae rei p. eligeret, medio Martio campo adhibita publicorum sacerdotum frequentia inferias Neroni dedit... Tácito (Hist. 2.95.1) refere o sacrifício, sem sugerir que era para que não houvesse dúvidas sobre o modelo de governo.
} 
Minerva protectora da cidade!') ${ }^{9}$, e o refinamento das iguarias vindas dos extremos do império e de fora dele, através dos meios do Estado. Mas o pior é a sua gula: um apetite descontrolado e sórdido que não tinha em conta o contexto ou o momento ${ }^{10}$.

No que diz respeito ao segundo vício enunciado, a saeuitia ${ }^{11}$, Vitélio manifesta uma crueldade arbitrária, exercida contra quem quer que seja e a qualquer pretexto ${ }^{12}$. E o topos da gula cruza-se com a crueldade, quando se afirma que manda executar uma vítima à sua frente, porque «queria dar alimento aos olhos»" ${ }^{13}$. De acordo com a aproximação a Nero, chega a ser sugerido o matricídio, crime que marca o clímax da saeuitia nesta Vida ${ }^{14}$.

Consequentemente, a narrativa da morte de Vitélio vem pejada de atitudes vis, de cobardia e impiedade. Nas lutas com os Flávios, é mesmo acusado por Suetónio de incendiar o templo do Capitólio (quando a tradição paralela apresenta de modo diferente a origem do incêndio ${ }^{15}$ ) e, ampliando mais uma vez os lugares-comuns da gula e o de Nero incendiário, afirma-se que contempla o combate no meio de um banquete (Suet. Vit. 15.3). Suetónio cede assim claramente à propaganda

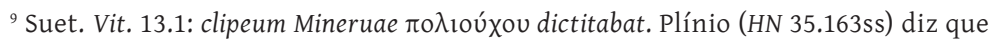
o prato custou um milhão de sestércios; Díon Cássion (65.3.3) assegura que a bandeja perdurou até ao tempo de Adriano.

${ }^{10}$ Suet. Vit. 13.3: Vt autem homo non profundae modo sed intempestiuae quoque ac sordidae gulae.

${ }^{11}$ Saeuitia é a crueldade associada na origem aos animais selvagens e vício principal dos típicos tiranos retóricos.

${ }^{12}$ Suet. Vit. 14.1: Pronus uero ad cuiuscumque et quacumque de causa necem atque supplicium. Há nítida semelhança com o que Suetónio diz de Nero 37.1: Nullus posthac adhibitus dilectus aut modus interimendi quoscumque libuisset quacumque de causa. Pelo contrário, segundo Díon Cássio, 66.6.2, suprimiu reduzido número de partidários de Otão.

${ }^{13}$ Suet. Vit. 14.2: 'Velle se' dicens 'pascere oculos'. A expressão é referida por Tácito como justificação de Vitélio para a visita a um inimigo doente (Tac. Hist. 3.39.1).

${ }^{14}$ Suet. Vit. 14.5. Tácito, Hist. 3.67.2, fala de uma morte afortunada, que, ocorrendo pouco antes da do filho, a poupou de assistir à aniquilação da família.

${ }^{15}$ Numa das versões seriam os próprios sitiados a atear o incêndio (Tac. Hist. 3.71.4). 
dos Flávios. Mas este é um pretexto para fazer da morte de Vitélio um castigo dos deuses ${ }^{16}$, ao dar um apoio prévio às acusações da multidão, referidas mais à frente.

São-lhe atribuídas sucessivas intenções de abdicar não levadas a cabo, e, perdidas as esperanças, uma fuga para o Aventino, para a casa paterna, escondido numa liteira - uma retirada que parece uma paródia da de Nero para casa de Fáon ${ }^{17}$, mas, no caso de Vitélio, o único, e significativo, entourage era constituído por um padeiro e um cozinheiro.

De regresso ao palácio, encontrando-o deserto, barrica-se indignamente, na cela do porteiro, depois de prender um cão diante da entrada e de colocar um leito e um colchão contra a porta ${ }^{18}$. 0 assassínio é impressionante pela crueza e aviltamento.

\section{TEXTO}

Irruperant iam agminis antecessores ac nemine obuio rimabantur, ut fit, singula. Ab his extractus e latebra, sciscitantes, quis esset - nam ignorabatur - et ubi esse Vitellium sciret, mendacio elusit; deinde agnitus rogare non destitit, quasi quaedam de salute Vespasiani dicturus, ut custodiretur interim uel in carcere, donec religatis post terga manibus, iniecto ceruicibus laqueo, ueste discissa seminudus in forum tractus est inter magna rerum uerborumque ludibria per totum uiae Sacrae spatium, reducto coma capite, ceu noxii solent, atque etiam mento mucrone gladii subrecto, ut uisendam praeberet faciem neue summitteret; quibusdam stercore et caeno incessentibus, aliis incendiarium et patinarium uociferantibus, parte uulgi etiam corporis uitia exprobrante. erat

${ }^{16}$ Como sugere Cizek 1975: 128-129.

${ }^{17}$ Vide Brandão 2008.

${ }^{18}$ Suet. Vit. 16.1. Tácito, Hist. 3.84.4, refere-se vagamente ao esconderijo como pudenda latebra, palavra que Suetónio também usa depois. Díon Cássio (65. 20.2) refere mesmo que foi mordido pelos cães.; cf. Della Corte 1967: 133, n. 85. 
enim in eo enormis proceritas, facies rubida plerumque ex uinulentia, uenter obesus, alterum femur subdebile impulsu olim quadrigae, cumauriganti Gaio ministratorem exhiberet. tandem apud Gemonias minutissimis ictibus excarnificatus atque confectus est et inde unco tractus in Tiberim. ${ }^{19}$

\section{TRADUÇÃO}

Irromperam então os da vanguarda do exército e, sem topar com ninguém pela frente, esquadrinhavam tudo, como acontece nestes casos. Tendo sido por eles retirado do esconderijo, quando se lhe puseram a perguntar quem era (pois não estava a ser reconhecido) e onde julgava que Vitélio estava, tratou de enganá-los com uma mentira. Depois de reconhecido, não deixou de rogar, a pretexto de ter revelações a fazer sobre a segurança de Vespasiano, que o protegessem entretanto, nem que fosse no cárcere. Até que, de mãos atadas atrás das costas, um laço apertado ao pescoço, meio despido, de roupas rasgadas, foi arrastado para o foro, no meio de grandes ultrajes por actos e palavras, ao longo de toda a Via Sacra: puxaramlhe a cabeça para trás pelos cabelos, como se costuma fazer aos criminosos, e ainda lhe mantiveram o queixo levantado com a ponta de um gládio, para que deixasse ver a cara e não a baixasse. Enquanto alguns lhe atiravam estrume e lama, outros lhe gritavam os apelidos de incendiário e alarve; parte do povo até lhe censurava os defeitos do corpo. Tinha, pois, grande corpulência e o rosto geralmente avermelhado da embriaguez, a barriga gorda, e uma das coxas um tanto ou quanto fraca devido ao choque de uma quadriga quando dava outrora apoio a Gaio que conduzia um carro. Finalmente, junto às Gemónias, foi dilacerado com miudíssimos golpes e morto, e dali foi arrastado para o Tibre com um gancho.

${ }^{19}$ Vit. 17.1-2. Cf. Tac. Hist. 3.84.5-85. 


\section{COMENTÁRIO}

"Irromperam então os da vanguarda do exército": no dia 20 de Dezembro de 69 d.C., as tropas dos Flávios irrompem pela cidade divididas em três colunas, dispostas a vingarem os seus camaradas mortos no dia anterior, na sequência do incêndio do Capitólio, entre os quais Flávio Sabino, irmão do futuro imperador. Temos como termo de comparação as narrativas paralelas de Tácito (Hist. 3.84-85) e Díon Cássio (65.20-21).

"Tendo sido por eles retirado do esconderijo": Tácito (Hist. 3.84) diz que foi Júlio Plácido, tribuno de uma coorte, quem o retirou do esconderijo, o que apesar de tudo confere alguma dignidade, por não ter sido arrastado pela turba dos soldados.

"Depois de reconhecido, não deixou de rogar": Suetónio não perde oportunidade de aumentar a indignidade de carácter de Vitélio - a atitude de súplica com a promessa de revelações e o pedido de que o guardem na prisão não figura nos outros autores.

"Até que, de mãos atadas atrás das costas": trata-se de uma narrativa de linchamento, na qual o biógrafo concentra informação realista para acentuar a degradação de Vitélio, como mostra o facto de ir amarrado, com um laço ao pescoço, de roupas rasgadas, arrastado, sujeito a insultos por actos e palavras. Tácito faz notar que ninguém vertia uma lágrima; o desdouro de tal fim afastara toda a compaixão ${ }^{20}$.

"Puxaram-lhe a cabeça para trás pelos cabelos, como se costuma fazer aos criminosos": Plínio o Moço (Pan. 34.3) refere esta prática aplicada aos condenados. Tácito (Hist. 3.85) acrescenta que o obrigavam, assim, ora a oferecer o rosto aos ultrajes, ora a ver as suas estátuas serem derrubadas, os rostra, ou o lugar onde Galba tinha sido assassinado. É queda em total desgraça, do mais alto poder ao mais vil castigo.

"Outros lhe gritavam os apelidos de incendiário e alarve": pela voz da multidão se estabelece a ligação entre a culpa do incêndio do

\footnotetext{
${ }^{20}$ Nullo inlacrimante; deformistas exitus misericordiam abstulerat.
} 
Capitólio, que Suetónio imputa exclusivamente a Vitélio, e o vício da gula, por um lado, e o género de morte, por outro, a significar castigo daquelas atitudes.

"parte do povo até lhe censurava os defeitos do corpo": apesar de a rubrica da descrição física de alguns imperadores aparecer próxima na narrativa da morte (ou antes ou depois), é este o único caso em que aparece oportunamente intercalada no próprio relato. E é motivada pelos insultos populares que se relacionam com o seu aspecto e os seus vícios, de incendiário e guloso.

“Tinha, pois, grande corpulência”: o retrato físico é, de facto, constituído apenas por defeitos corporais, expostos de forma ridícula e humilhante ${ }^{21}$. É um retrato mais grotesco que o de Cláudio, o qual ainda apresentava aspectos positivos. O conjunto fala por si. Os uitia corporis são manifestação das manchas morais: a enormis proceritas, a facies rubida plerumque ex uinulentia, o uenter obesus são o efeito do seu exagerado culto do prazer da mesa ${ }^{22}$. Assim, a execução pública de Vitélio transforma-se também na destruição física dos efeitos da gula. A perna aleijada recorda o seu gosto pelas corridas do circo e, através deste desporto, a associação a Calígula. O retrato em si constitui mais um item do linchamento para o qual o biógrafo contribui também ao inserir a descrição física nesta secção.

"Finalmente, junto às Gemónias": depois da descrição física, segue-se a execução junto às Gemónias, o local destinado aos mais vis criminosos. Suetónio não menciona a atitude caridosa de um soldado da Germânia, que tenta, como sugere Díon Cássio, subtrair o imperador aos ultrajes com uma morte rápida (ou talvez atacar o tribuno, segundo a hipótese de Tácito). E omite uma última uox que lhe conferiria alguma dignidade: segundo Tácito, aos insultos de um tribuno Vitélio responde que, apesar de tudo, fora seu imperator ${ }^{23}$. O historiador latino foca mais a censura na

\footnotetext{
${ }^{21}$ Vide Newbold 1984: 120.

${ }^{22}$ Vide Martin 1991: 215-216.

${ }^{23}$ Cf. D.C. 65.21.2.
} 
vileza da multidão: et uolgus eadem prauitate insectabatur interfectum qua fouerat uiuentem («o vulgo atirou-se a ele, já morto, com a mesma indecência com que o tinha festejado quando vivo» $)^{24}$. Os relatos completam-se: o biógrafo descreve de forma crua os derradeiros agravos. A expressão minutissimis ictibus excarnificatus parece reveladora da habitual apetência de Suetónio pelos pormenores realistas, por mórbidos que sejam. O mesmo se pode dizer da derradeira humilhação: foi arrastado com um gancho para o Tibre, o maior insulto que se podia fazer a um condenado morto: era o castigo dos tiranos - o que os cesaricidas tinham destinado para o cadáver de César ${ }^{25}$, e que o povo chegara a propor para o corpo de Tibério. o dramatismo da morte é ainda acentuado pelo facto de o biógrafo salientar que pereceu com o irmão e o filho, estabelecendo, para o caso do segundo, uma falsa coincidência ${ }^{26}$.

Para Cizek a morte ignóbil de Vitélio é o ponto de partida para a descrição da vida odiosa que Suetónio nos oferece deste imperador; esta morte oferece ao biógrafo o meio, e mesmo a obrigação, de o incriminar constantemente e de o tornar desprezível e um perseguido do destino e dos deuses ${ }^{27}$.

O final desta Vida mostra como o destino é para o biógrafo um agente poderoso. A biografia termina com a revelação do significado de um presságio ocorrido em Viena, cujo significado o biógrafo deixara propositadamente em suspenso: um galo saltara para o ombro e para a cabeça de Vitélio (Vit. 9). Não se enganaram os que disseram que cairia às mãos de um gaulês (jogando com a ambiguidade do nome gallus). Com efeito, fora derrotado por António Primo, que nascera em Tolosa e tivera na infância a alcunha de Beccus (id ualet gallinacei rostrum). o biógrafo dá mais relevo a este pormenor do que à batalha de Cremona

${ }^{24}$ Vide Martin 1991: 380-385.

${ }^{25}$ Vide Brandão 2011: 31-37.

${ }^{26} \mathrm{O}$ filho de Vitélio não morreu ao mesmo tempo que o pai, mas mais tarde, como se lê em Tac. Hist. 4.80. Cf. Gascou 1984: 322, n. 18.

${ }^{27}$ Cizek 1975: 129. 
(que nem menciona), onde António Primo foi vencedor ${ }^{28}$. Curiosamente, Suetónio (Vit. 11.2) tinha dito que Vitélio não respeitou o dia nefasto da derrota de Roma pelos Gauleses junto ao rio Ália, em 490 a.C.

A deslocação dos presságios de morte para final absoluto dá-lhe um significado especial. E, ao retardar a interpretação do presságio até ao fim, Suetónio dá maior unidade à biografia e salienta a influência do fatum ou da providência divina sobre a vida e morte de Vitélio e sobre este período conturbado cujo relato começa e termina com presságios de aves. A vida de Galba começara com a história da galinha branca, símbolo do vigor dos Júlio-Cláudios. Mas, depois deste período atroz, a estabilidade veio com Vespasiano, o fundador da dinastia que haveria de se finar em 96 com o assassínio de Domiciano, como o biógrafo sugere logo no início da Vida do primeiro.

\section{BIBLIOGRAFIA}

Brandão, J. L. (2008), “Páginas de Suetónio: o último dia do artifex Nero”, BEC 49: 49-59.

Brandão, J. L. (2009), Máscaras dos Césares. Coimbra, CECH.

Brandão, J. L. (2011), “Páginas de Suetónio: a morte de César”, BEC 55: 31-37.

Cizek, E. (1975), "La mort de Vitellius dans les Vies des douze Césars de Suétone" REA 77: 125-130.

Cizek, E. (1977), Structure et idéologie dans les Vies des douze Césars de Suétone. Paris, Les Belles Lettres.

Damon, C. (2014), "Suetonius the ventriloquist", in Power, T. \& Gibson, R. K. (eds.), Suetonius the Biographer. Oxford, University Press, 38-57.

Della Corte, F. (1967), Svetonio eques Romanus. Firenze.

Dunkle, J. R. (1971), "The rethorical tyrant in Roman Historiography: Sallust, Livy and Tacitus", CW 65: 12-20.

${ }^{28}$ Suet. Vit. 18. Vide Gascou 1984: 358-359; Power 2015: 61-62. 
Gascou, J. (1984), Suétone historien. Paris, de Boccard.

Murison, Ch. L. (1992), Suetonius Galba, Otho, Vitellius, ed. with intr. and notes. London, Bristol Classical Press.

Newbold, R. F. (1984), “Suetonius' boundaries”, Latomus 43: 118-132.

Power, T (2014), “The endings of Suetonius Caesars", in in Power, T. \& Gibson, R. K. (eds.), Suetonius the Biographer. Oxford, University Press, 58-77.

Scuderi, R. (1995), "Le Vite Plutarchee di Galba e di Otone: teoria e prassi politica nella successione imperiale", Gallo, I \& Scardigli, B. (cura), Atti del $V$ convegno plutarcheo. Napoli, M. D’Auria Editore, 399-413.

Stadter, Ph. A. (2005), “Rivisiting Plutarch's Lives of the Caesars": Pérez Jiménez, A \& Titchener, F. (eds.), Valori letterari delle opera di Plutarco. Studi offerti al professore Italo Gallo dall' The International Plutarch Society. Málaga-Logan, 419-435.

Tabacco, R. (1985), "Il tiranno nelle declamazioni di scuola in lingua latina": Memorie della Accademia delle Scienze Morali, Storiche e Filologiche di Torino II. Classe di Scienze Morali, Storiche e Filologiche, serie V, vol.9. Torino, 1-141.

Venini, P. (1974), "Sulle Vite suetoniane di Galba, Otone e Vitellio" RIL 108: 991-1014.

Venini, P. (1977), C. Svetonio Tranquillo. Vite di Galba, Ottone, Vitellio, con comm. Torino, Paravia.

Wellesley, K. (2000), The year of the four emperors, with a new introduction by B. Levick. London/New York, Routledge. 